$<$ Regular Article for Polymer $>$

\title{
In situ nano-objects via RAFT aqueous dispersion polymerization of 2-methoxyethyl acrylate using poly(ethylene oxide) macromolecular chain transfer agent as steric stabilizer
}

Shinji Sugihara, ${ }^{a, b_{*}}$ Akmal Hadi Ma'Radzi, ${ }^{c}$ Shota Ida, ${ }^{a}$ Satoshi Irie, ${ }^{d}$ Takamaru Kikukawa, ${ }^{a}$ Yasushi Maeda ${ }^{a}$

${ }^{a}$ Department of Applied Chemistry and Biotechnology, Graduate School of Engineering, University of Fukui, 3-9-1 Bunkyo, Fukui 910-8507, Japan

${ }^{b}$ Japan Science and Technology Agency, PRESTO, 4-1-8 Honcho Kawaguchi, Saitama 332-0012, Japan

${ }^{c}$ School of Bioprocess Engineering, Universiti Malaysia Perlis, Kompleks Pusat Pengajian Jejawi 3, 02600 Arau Perlis, Malaysia

d Department of Frontier Fiber Technology and Science, Graduate School of Engineering, University of Fukui, 3-9-1 Bunkyo, Fukui 910-8507, Japan

*Correspondence to Shinji Sugihara (E-mail: sugihara@u-fukui.ac.jp)

Keywords: Dispersion polymerization, Reversible addition fragmentation chain transfer (RAFT), Self-Assembly 


\section{ABSTRACT}

Poly(ethylene oxide)-poly(2-methoxyethyl acrylate) diblock copolymers (PEO-b-PMEA) are synthesized by RAFT aqueous dispersion polymerization of MEA using poly(ethylene oxide) macromolecular chain transfer agent as a reactive steric stabilizer. Both segments are well-known to be bio- and blood-compatible polymers. This formulation enables the production of various particle morphologies such as spheres, worms, and vesicles from the same block copolymer in water. The synthesis starts when both the reactive steric stabilizer and MEA monomer are dissolved in water; however, the growing polymer is not water-soluble and begins to form nano-objects. In the case of the synthesis of $\mathrm{PEO}_{113}-b-\mathrm{MEA}_{300}$ diblock copolymers, the nano-objects change from spheres into larger aggregates of worms when the solids concentration in the polymerization increases from 5 to $15 \mathrm{wt} \%$ at full monomer conversion. The morphology finally turns into vesicles as the solids concentration increases to $20 \mathrm{wt} \%$. The final block copolymer morphology at full monomer conversion is dictated by not only degree of polymerization of MEA but also the solids concentration in the polymerization mixture.

\section{Introduction}

Reversible addition fragmentation chain-transfer (RAFT) polymerization is considered to be one of the most established and efficient methods to prepare block copolymers with a controlled molecular weight and molecular weight distribution [1]. In general, block copolymers in selective solvents self-assemble to form spherical micelles, rod/worm-like micelles, vesicles and other higher-order structures [2-21]. However, the self-assemblies can only be achieved in dilute solution (typically, copolymer concentration $\leq 1.0 \mathrm{wt} \%$ [2]) by complicated and time consuming processes. Therefore, RAFT aqueous dispersion polymerization presents an efficient strategy 
through the polymerization induced self-assembly (PISA) process in water [6-13]. This process enables direct preparation of well-defined block copolymer self-assemblies at high solids concentration. Furthermore, post-polymerization processing is not required and PISA has been achieved in various solutions such as aqueous solutions, non-polar organic solvents, or alcoholic media [14-18]. Another method, RAFT emulsion polymerization, also leads to various morphologies [19]. Thus, PISA is suitable for large scale applications including drug delivery systems (DDS) [20]. Some comprehensive reviews on PISA including the RAFT dispersion and emulsion polymerizations have been written [21].

In the past few years, Sugihara and Armes et al. introduced PISA via RAFT aqueous dispersion polymerization that was dependent on both the degree of polymerization $(D P)$ of the core block and the solids concentration [6-8]. This was achieved through the chain extension of the hydrophilic homopolymer, poly(2-(methacryloyloxy)ethyl phosphorylcholine) (PMPC) with the soluble monomer, (2-hydroxypropyl methacrylate) (HPMA) in water. The self-assembly was induced when PHPMA became insoluble in water during the course of the polymerization. The authors concluded that the diblock copolymer formulation can predict the production of nano-objects with higher-order structures such as worms and vesicles that were previously difficult to prepare due to the narrow phase region. We have generalized this study on PISA by using a useful poly(ethylene oxide) macromolecular-chain transfer agent (PEO macro-CTA) as a steric stabilizer and 2-methoxyethyl acrylate (MEA) as a monomer for PEO-b-PMEA. For RAFT aqueous dispersion polymerization of MEA, there is an interesting example using poly(poly(ethylene glycol)methyl ether methacrylate) (PPEGMA) as a macromolecular-chain transfer agent (macro-CTA) [22]. The polymerization enabled the production of nanoparticles 40-60 nm in diameter. However, to our knowledge, there are few reports on the preparation of 
various morphologies of PEO- $b$-PMEA not only via RAFT dispersion polymerization and but also by conventional RAFT solution polymerization.

PEO exhibits blood compatible and biocompatible properties because it is nontoxic and nonimmunogenic, thus it is used in biomedical and pharmaceutical applications such as DDS. PEO improves the enhanced permeability and retention (EPR) effect in tumor tissue through PEGylation [23,24]. PEGylated nanoparticles are stable, and further aggregation in the blood stream can be prevented. PMEA also exhibits blood compatibility and low protein adsorption, and has been widely used in commercial biomedical applications [25,26]. The most important feature is that the MEA monomer is highly water soluble, but the PMEA is not [22,27]. This characteristic is suitable for RAFT dispersion polymerization to induce self-assemblies for biomedical applications.

In this study, we demonstrate chain extension using RAFT aqueous dispersion polymerization of MEA in the presence of PEO macromolecular RAFT agent as a reactive steric stabilizer. As the PMEA chains grow during the course of the polymerization, the hydrophobicity is increased. Thus, the resulting PEO-b-PMEA diblock copolymers form in situ self-assemblies in water. These polymer nano-objects are controlled not only by the length of the PEO block, but also by the total solids concentration of the polymerization of MEA (Fig. 1). The resulting block copolymer aggregates in water are kinetically frozen at the ambient temperature. However, using RAFT dispersion polymerization conducted at high temperature, the aggregates can change their morphology. This is considered to be due to the inter-micelle fusion, which means inelastic collisions between solvated/plasticized nanoparticles leads to an increase in the packing parameter [21(c)]. Thus, unlike other methods, this formulation allows the production of higher-order structures such as worms and vesicles, directly and efficiently in high concentration from the same block copolymer. These predetermined morphologies of the 
diblock copolymer in water will offer a new prospect for biomedical applications such as nanocarriers in DDS.
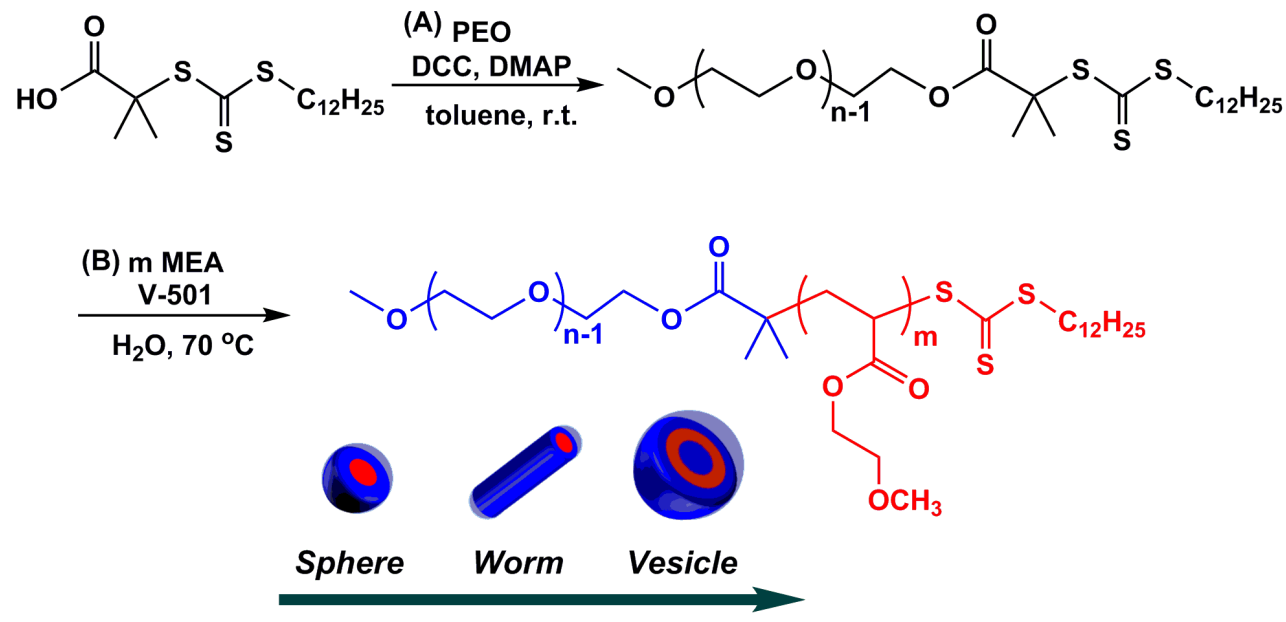

Solids concentration in polymerization

$D P$ of PMEA

Fig. 1. Synthesis of the PEO macro-CTA (A) and RAFT aqueous dispersion polymerization of MEA using the PEO macro-CTA at $70{ }^{\circ} \mathrm{C}(\mathrm{B})$. Various morphologies can be directly prepared, depending on either the total solids concentration or the DP of the PMEA block.

\section{Experimental}

\subsection{Materials}

2-Methoxyethyl acrylate (MEA) was purchased from Wako (> 98\%). The MEA was purified by passage through a prepacked inhibitor-removal column (Sigma-Aldrich) before use. Toluene (Wako; > 99.5\%, super dehydrated) was distilled over calcium hydride just before use. 
Poly(ethylene oxide) monomethyl ether (PEO-OH, Aldrich; $M_{\mathrm{n}}=2000 \mathrm{~g} \mathrm{~mol}^{-1}$ and $5000 \mathrm{~g}$ mol $^{-1}$ ), 4-dimethylaminopyridine (DMAP, Nacalai tesque; $>\quad 98 \%$ ) and $N, N^{\prime}$-dicyclohexylcarbodiimide (DCC, Wako) were used without further purification. 4,4'-Azobis(4-cyanovaleric acid) (V-501, Wako; > 98\%) was purified by recrystallization from methanol. RAFT agent, 2-(dodecylthiocarbonothioylthio)-2-methylpropionic acid, was synthesized according to a literature protocol [28].

\subsection{Synthesis of PEO macro-CTA and RAFT aqueous polymerization}

PEO macro-chain transfer agents with molecular weights of $2000 \mathrm{~g} \mathrm{~mol}^{-1}$ and $5000 \mathrm{~g} \mathrm{~mol}^{-1}$ were synthesized following the literature protocol as shown in Figure 1(a) $[29,30]$. The structure of the PEO was determined by ${ }^{1} \mathrm{H}$ NMR spectroscopy. The typical procedure for RAFT aqueous dispersion polymerization using the PEO macro-CTA is as follows. For commercial PEO having a methyl ether terminus with molecular weight of $2000 \mathrm{~g} \mathrm{~mol}^{-1}$ (Sigma-Aldrich), the actual DP of the macro-CTA was 45 as judged by the ratio of oxyethylene moieties and methoxy terminus from ${ }^{1} \mathrm{H}$ NMR spectroscopy. This $\mathrm{PEO}_{45}$ macro-CTA (0.15 g, equivalent to 0.065 mmol PEO repeat units $)$ was mixed with V-501 (6.0 mg, 0.021 mmol; macro-CTA/initiator molar ratio = 3.0), varying amounts of MEA (0.634-2.115 g, 4.872-16.252 mmol; target DP 75-250), and deionized water (1.829-20.385 g; 10-30 wt\%) for the desired total solids concentration in a $25-50 \mathrm{~mL}$ round-bottomed flask, which was equipped with a magnetic stir bar. These solutions were stirred in an ice-bath until all reagents had dissolved. After sparging with nitrogen for approximately $30 \mathrm{~min}$, each polymerization was allowed to proceed at $70{ }^{\circ} \mathrm{C}$ and then quenched after $23 \mathrm{~h}$ via cooling at room temperature and exposure to air. For the longer PEO with a methyl ether terminal with molecular weight of $5000 \mathrm{~g} \mathrm{~mol}^{-1}$ 
(Sigma-Aldrich), we determined the $D P(=113)$ by the same protocol and conducted the polymerization of MEA using the $\mathrm{PEO}_{113}$ macro-CTA.

\subsection{Polymer characterization}

Molecular weight distributions (MWDs) of the copolymers were assessed by size exclusion chromatography (SEC) in $N, N$-dimethylformamide (DMF) with $10 \mathrm{mM} \mathrm{LiBr}$ at $40{ }^{\circ} \mathrm{C}$ using two polystyrene gel columns [TSK gel G-MH $\mathrm{HR}_{\mathrm{HR}} \mathrm{M}$; flow rate $1.0 \mathrm{~mL} / \mathrm{min}$ ] connected to a Tosoh CCPM-II pump and RI-8012 and UV-8000 for refractive and UV detectors, respectively. Number-average molecular weight $\left(M_{\mathrm{n}}\right)$ and polydispersity $\left(M_{\mathrm{w}} / M_{\mathrm{n}}\right)$ were calculated from GPC curves on the basis of polystyrene (PSt) and PEO calibrations for block copolymer and PEO macro-CTA, respectively. ${ }^{1} \mathrm{H}$ NMR spectra to determine the structures such as the number-average end functionality of the RAFT (dithioester) terminal $\left(F_{\mathrm{n}}\right)$ and the compositions of block copolymers were recorded on a JEOL JNM-EX500 spectrometer (500 MHz). DLS studies were performed using a Zetasizer Nano-ZS instrument (Malvern Instruments) at $25^{\circ} \mathrm{C}$ at a scattering angle of $173^{\circ}$. The mean hydrodynamic diameter $\left(D_{\mathrm{h}}\right)$ and polydispersity index (PDI, $\mu_{2} / \Gamma^{2}$ ) of the micelles were calculated by cumulants analysis of the experimental correlation function using Zeta Software version 7.02. Atomic force microscopy (AFM) images were recorded using the dynamic mode at ambient conditions with an SPM-9700 (Shimadzu) scanning probe microscope. A silicon AFM probe tip (Olympus, OMCL-AC160TS-C3) with a radius of $7 \mathrm{~nm}$, a spring constant of $26 \mathrm{~N} / \mathrm{m}$, and a resonance frequency of $300 \mathrm{kHz}$ were used. A sample for AFM imaging was prepared by placing a $20 \mu \mathrm{L}$ drop of the block copolymer solution (0.05 wt\% polymer solution) on freshly cleaved muscovite mica (ca. $1 \mathrm{~cm} \times 1 \mathrm{~cm}$, V-4 grade, Alliance Biosystems) and allowing it to dry in air for a day. For scanning electron microscopy (SEM) studies, the aqueous dispersions (0.1 wt\% of polymer solution) were 
mounted directly on aluminum stubs, dried under air for one day and sputtered with gold under vacuum. They were then visualized in high vacuum using a JEOL JSM-6390 scanning electron microscope. Transmission electron microscopy (TEM) studies were conducted using a JEOL JEM2100 instrument operating at $200 \mathrm{kV}$ equipped with a Gatan ORIUS SC200D CCD camera. Copper grids with carbon-coated support film (ELS-C10, Okenshoji) were glow discharged for 15 sec to create a hydrophilic surface. About $5 \mu \mathrm{L}$ of aqueous diblock copolymer dispersions (0.5 wt\%) was put on the grid for $30 \mathrm{sec}$ and then blotted with filter paper. The grid was then immersed for $60 \mathrm{~s}$ in Gd based stainer (EM stainer, Nisshin EM) for negative staining. The stained grid was then blotted with filter paper and dried.

\section{Results and discussion}

First, the RAFT agent, 2-(dodecylthiocarbonothioylthio)-2-methylpropionic acid, was prepared for the RAFT aqueous dispersion polymerizations, and then PEO macro-CTAs were prepared via the esterification process of the carboxylic acid group from the RAFT agent with PEO monomethyl ether in toluene at room temperature. The structure and DPs of the resulting PEO macro-CTAs were determined by ${ }^{1} \mathrm{H}$ NMR spectroscopy (Fig. 2B). The molecular weights of the PEO macro-CTAs were $2300\left(M_{\mathrm{w}} / M_{\mathrm{n}}=1.05\right)$ and $5500\left(M_{\mathrm{w}} / M_{\mathrm{n}}=1.08\right)$ calculated from GPC curves on the basis of a PEO calibration, whose actual DPs were determined as 45 and 113, respectively, via ${ }^{1} \mathrm{H}$ NMR spectroscopy. The end-functionality of $\mathrm{PEO}_{45}$ macro-CTA $\left(F_{\mathrm{n}}=0.94\right)$ was larger than that of $\mathrm{PEO}_{113}$ macro-CTA $\left(F_{\mathrm{n}}=0.90\right)$, calculated from the ratio of the peak intensities of $\omega$-end methylene $(\boldsymbol{g})$ and $\alpha$-end methyl protons (a) in Fig. 2B. 


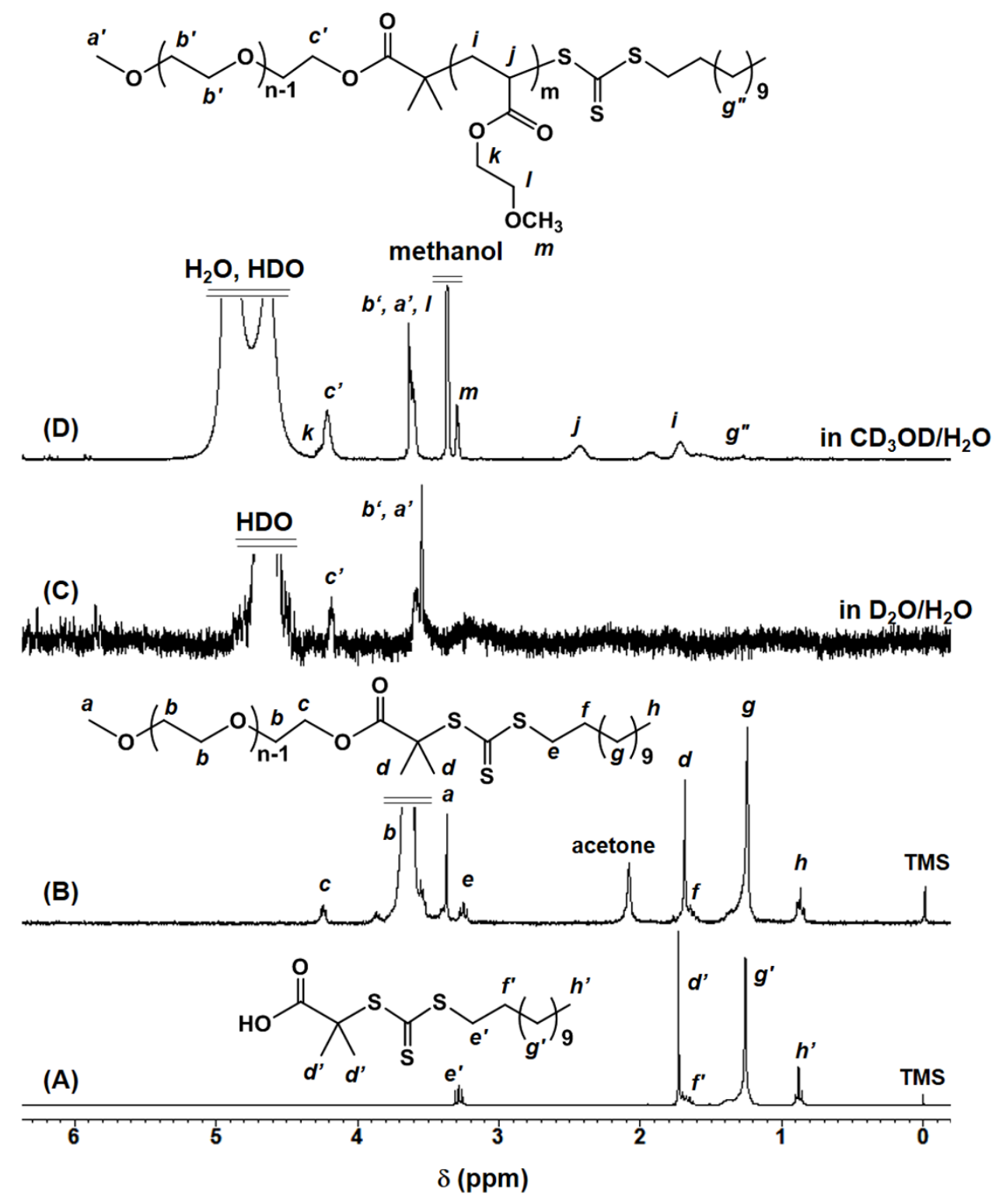

Fig. 2. ${ }^{1} \mathrm{H}$ NMR spectra at $25{ }^{\circ} \mathrm{C}$ of (A) 2-(dodecylthiocarbonothioylthio)-2-methylpropionic acid, (B) $\mathrm{PEO}_{45}$ macro-CTA with molecular weight of $2300\left(M_{\mathrm{w}} / M_{\mathrm{n}}=1.05\right) . \mathrm{PEO}_{45}-b-\mathrm{MEA}_{75}$ (entry 1 in Table 1 ) in aqueous polymerization mixture diluted in $\mathrm{D}_{2} \mathrm{O}(\mathrm{C})$ or diluted in $\mathrm{CD}_{3} \mathrm{OD}$ (D). 
Next, using the resulting PEO macro-CTA, RAFT aqueous dispersion polymerization of MEA was conducted by V-501 initiator in water at $70{ }^{\circ} \mathrm{C}$ under various solids concentrations. The solids concentration is defined as $100 \times[$ PEO macro-CTA (g) + MEA (g)]/[all reaction mixture (g)]. In the case of the RAFT aqueous dispersion polymerization of MEA, the MEA is expected to be the core monomer for PEO-stabilized self-assembly. As the MEA chain grows from water-soluble PEO macro-CTA, at a certain point, it reaches a critical DP and becomes sufficiently hydrophobic so as to induce micellar nucleation. The targeted DP of MEA, i.e., $[\mathrm{MEA}]_{0} /[\mathrm{PEO} \text { macro-CTA }]_{0}$, was set from 75 to 400 . During the course of the dispersion polymerization, the solution changed from transparent to opaque, indicating the progress of the polymerization and in situ self-assembly induced by micellar nucleation of PMEA. Finally, the polymerization reached the full monomer conversion of MEA and the final morphology. The self-assembled morphologies induced by the polymerization were confirmed by means of AFM (dynamic mode), TEM, and SEM. The representative polymerization results including morphologies are summarized in Table 1. 


\section{Table 1}

Representative RAFT aqueous dispersion polymerization of MEA at $70{ }^{\circ} \mathrm{C}$ using PEO macro-CTA. ${ }^{\text {a }}$

\begin{tabular}{|c|c|c|c|c|c|c|c|c|}
\hline entry & sample & $\begin{array}{l}\text { solids } \\
(w t \%)^{b}\end{array}$ & $\begin{array}{c}\text { targeted } \\
\text { DP of MEA }\end{array}$ & $\begin{array}{c}\text { actual DP } \\
\text { of MEA }^{\mathrm{c}}\end{array}$ & $M_{\mathrm{n}}^{\mathrm{d}}$ & $M_{\mathrm{w}} / M_{\mathrm{n}}{ }^{\mathrm{d}}$ & $D_{\mathbf{h}}(\mathrm{PDI})^{\mathrm{e}}$ & morphology ${ }^{\mathrm{f}}$ \\
\hline 1 & $\mathrm{PEO}_{45}-b-\mathrm{MEA}_{75}$ & 25.0 & 75 & 76 & 10300 & 1.21 & 104 (029) & sphere $^{\mathrm{g}}$ \\
\hline 2 & $\mathrm{PEO}_{45}-b-\mathrm{MEA}_{100}$ & 10.0 & 100 & 102 & 14600 & 1.22 & $146(0.22)$ & sphere \\
\hline 3 & $\mathrm{PEO}_{45}-b-\mathrm{MEA}_{150}$ & 20.0 & 150 & 151 & 19700 & 1.24 & $190(0.24)$ & sphere \\
\hline 4 & $\mathrm{PEO}_{45}-b-\mathrm{MEA}_{250}$ & 10.0 & 250 & 254 & 34300 & 1.20 & $223(0.30)$ & sphere \\
\hline 5 & $\mathrm{PEO}_{113}-b-\mathrm{MEA}_{300}$ & 5.0 & 300 & 301 & 37500 & 1.31 & 129 (0.07) & sphere \\
\hline 6 & $\mathrm{PEO}_{113}-b-\mathrm{MEA}_{300}$ & 10.0 & 300 & 304 & 38900 & 1.57 & $161(0.07)$ & sphere $^{\mathrm{h}}$ \\
\hline 7 & $\mathrm{PEO}_{113}-b-\mathrm{MEA}_{300}$ & 15.0 & 300 & 306 & 36600 & 1.50 & $209(0.31)$ & sphere + worm $^{\mathrm{i}}$ \\
\hline 8 & $\mathrm{PEO}_{113}-b-\mathrm{MEA}_{300}$ & 17.5 & 300 & 305 & 36400 & 1.55 & 323 (0.39) & Worm $^{j}$ \\
\hline 9 & $\mathrm{PEO}_{113}-b-\mathrm{MEA}_{300}$ & 20.0 & 300 & 306 & 36500 & 1.51 & $276(0.37)$ & Vesicle $^{k}$ \\
\hline 10 & $\mathrm{PEO}_{113}-b-\mathrm{MEA}_{300}$ & 25.0 & 300 & 299 & 35900 & 1.58 & $280(0.07)$ & Vesicle \\
\hline 11 & $\mathrm{PEO}_{113}-b-\mathrm{MEA}_{400}$ & 15.0 & 400 & 405 & 46400 & 1.58 & $197(0.07)$ & Sphere $^{l}$ \\
\hline 12 & $\mathrm{PEO}_{113}-b-\mathrm{MEA}_{400}$ & 20.0 & 400 & 400 & 44000 & 1.55 & $299(0.11)$ & Vesicle \\
\hline 13 & $\mathrm{PEO}_{113}-b-\mathrm{MEA}_{400}$ & 25.0 & 400 & 408 & 47000 & 1.59 & $329(0.04)$ & vesicle \\
\hline 14 & $\mathrm{PEO}_{113}-b-\mathrm{MEA}_{400}$ & 30.0 & 400 & 403 & 46300 & 1.58 & $343(0.09)$ & vesicle $^{\mathrm{m}}$ \\
\hline
\end{tabular}

${ }^{\mathrm{a}}[\mathrm{PEO} \text { macro-CTA }]_{0} /[\mathrm{V}-501]_{0}=3.0$, polymerization time $=24 \mathrm{~h} ;{ }^{\mathrm{b}} 100 \times[\mathrm{PEO}$ macro-CTA (g) + MEA (g) $] /[$ all reaction mixture (g)]; ${ }^{\mathrm{c}}$ Determined by ${ }^{1} \mathrm{H}$ NMR spectroscopy in $d_{4}$-methanol, assuming that the block efficiency is $100 \%$ : conversion $\geq 99 \%$; ${ }^{\mathrm{d}}$ Determined by GPC analysis (PSt calibration), calculated $M_{\mathrm{n}}=2300\left(\mathrm{PEO}_{45}\right)$ or 5500 $\left(\mathrm{PEO}_{113}\right)+130.14(\mathrm{MEA}) \times$ targeted DP of MEA; ${ }^{\mathrm{e}}$ Determined by DLS measurement at $25{ }^{\circ} \mathrm{C}$; ${ }^{\mathrm{f}}$ by AFM 
(dynamic mode), TEM, and SEM measurement; ${ }^{\mathrm{g}}$ Fig. 4B; ${ }^{\mathrm{h}}$ Fig. 5A; ${ }^{\mathrm{I}}$ Fig. 5B; ${ }^{\mathrm{j}}$ Fig. $6 \mathrm{~B} ;{ }^{\mathrm{k}}$ Fig. $6 \mathrm{C} ;{ }^{\mathrm{l}}$ Fig. $7 \mathrm{~A}$ and $7 \mathrm{C} ;{ }^{\mathrm{m}}$ Fig. 7B and 7D.

All the polymerizations using both $\mathrm{PEO}_{45}$ and $\mathrm{PEO}_{113}$ macro-CTAs had relatively good control over the polymer chain growth. Representative kinetic results using $\mathrm{PEO}_{45}$ macro-CTA are shown in Fig. 3. The kinetic studies using $\mathrm{PEO}_{45}$ macro-CTA afforded a linear semilogarithmic plot after an induction period (ca. 30 min), indicating first-order kinetics with respect to monomer. This polymerization rate did not change after the induction period $(\leq$ $95 \%$ conversion), indicating similar partition coefficient of monomer in solution and in monomer-swollen particles [14]. The $M_{\mathrm{n}}$ of the block copolymer, PEO-b-PMEA, was directly proportion to the monomer conversion and the molecular weight distributions were relatively narrow throughout the polymerization, but increased slightly toward the end of the polymerization as seen in Fig. 3B. At this stage, all the polymers obtained after $40 \mathrm{~min}$ polymerization under the condition (10 wt\% solids concentration) were spherical morphologies.

(A)

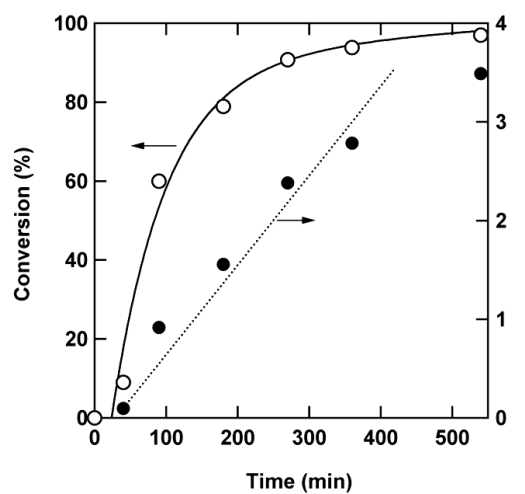

(B)

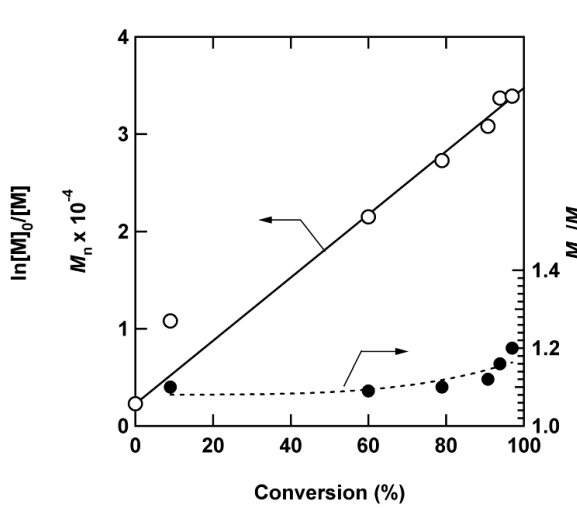

(C)

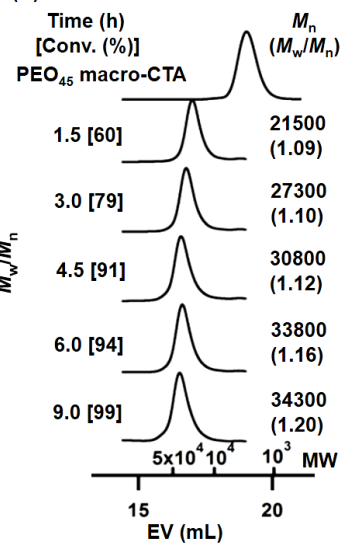


Fig. 3. Representative polymerization results to obtain PEO-b-PMEA of entry 4; (A) time vs. conversion and first-order kinetic plot, (B) evolution of $M_{\mathrm{n}}$ and $M_{\mathrm{w}} / M_{\mathrm{n}}$ with conversion, and (C) GPC curves for aqueous dispersion polymerization of MEA at $70{ }^{\circ} \mathrm{C}$ : $\left[\mathrm{PEO}_{45}\right.$ macro-CTA $]_{0} /[\mathrm{V}-501]_{0} /[\mathrm{MEA}]_{0}=3.0 / 1.0 / 750.0$ molar ratio, total solids concentration $=10.0$ wt\%.

In the case of $\mathrm{PEO}_{113}$ macro-CTA, the polymerizations of MEA also had sufficient control over the polymer chain growth. All MWDs of block copolymers were shifted toward higher molecular weight relative to the corresponding $\mathrm{PEO}_{113}$ macro-CTA (entries 5-14 in Table 1). However, $M_{\mathrm{n}} \mathrm{s}$ of the block copolymer were slightly higher than the calculated values and these MWDs were somewhat broader relative to those of $\mathrm{PEO}_{45}$ macro-CTA. These may be due to the difference of end-functionality between $\mathrm{PEO}_{45}$ and $\mathrm{PEO}_{113}$ macro-CTAs, and/or due to the morphology change in situ. The polymerization proceeds in monomer-swollen particles. As polymerization proceeds, uncontrolled reactions partly occur due to the high dense cores. Thus, final values of $M_{\mathrm{w}} / M_{\mathrm{n}}$ may be relatively high.

In addition, we confirmed the resulting block copolymers formed in situ PMEA-core aggregates in water as expected, by the comparison of ${ }^{1} \mathrm{H}$ NMR spectra of the resulting block polymer in $\mathrm{D}_{2} \mathrm{O}$ and $d_{4}$-methanol as shown in Fig. 2C and 2D, respectively. Specifically, compared to the signals of PEO macro-CTA in Fig. 2B, we confirmed all the signals associated with the PEO macro-CTA were observed in the spectra recorded in $\mathrm{D}_{2} \mathrm{O}$. In contrast, none of the PMEA signals were visible in $\mathrm{D}_{2} \mathrm{O}$. In practice, nano-sized particles were detected by dynamic light scattering (DLS) as shown in Table 1. However, all the proton signals expected for both 
the PEO and PMEA blocks were visible in the ${ }^{1} \mathrm{H}$ NMR spectrum recorded in $d_{4}$-methanol, since this is a good solvent for both blocks. These ${ }^{1} \mathrm{H}$ NMR observations suggest that the PEO chains act as the reactive and solvated steric stabilizer, while the PMEA chains form the non-solvated micelle core.

To determine all the morphologies, DLS studies were conducted to check the particle size and the polydispersity index (PDI). When $\mathrm{PEO}_{45}$ macro-CTA was used as a steric stabilizer in the RAFT aqueous dispersion polymerization of MEA, the target $D P$ of MEA was set from 75 to 250 (entries 1-4). The representative hydrodynamic diameters $\left(D_{\mathrm{h}}\right)$ for various $\mathrm{PEO}_{45}-b-\mathrm{MEA}_{\mathrm{m}}$ $(\mathrm{m}=75-250)$ diblock copolymer assemblies are shown in Fig. 4A. As the DP of PMEA increased from 75 to 250 , the $D_{\mathrm{h}}$ varied from 104 to 223, regardless of the solids concentration (10.0-30.0 wt\%). From the relationship between $D_{\mathrm{h}}$ and the mean DP of PMEA, it is clear that the mean $D_{\mathrm{h}}$ increased in nearly linear fashion with the increasing $D P$ of the core. The values of PDI are relatively narrow. It is well-documented that larger micelles are invariably obtained when the chain length of the core-forming block is increased, and the aggregation behavior is essentially the same as that in the post-aggregation using the block copolymer in a selective solvent [31]. However, all diameters determined by DLS were somewhat larger than PPEGMA-PMEA particles [22]. Thus, there may be some aggregation (fusion) of the original small spheres into bigger objects entrapping the block copolymers [32].

From the AFM (dynamic mode) studies on freshly cleaved muscovite mica under the dry condition, all the self-assemblies using $\mathrm{PEO}_{45}$ were spheres, regardless of the solids concentration in polymerization. For the example of $\mathrm{PEO}_{45}-b-\mathrm{PMEA}_{75}$ diblock copolymer, spherical micelles of $104 \mathrm{~nm}$ in $D_{\mathrm{h}}$ determined by DLS were obtained. The AFM images are shown in Fig. 4B. The size determined by AFM (ca. 50-100 nm) was smaller than the $D_{\mathrm{h}}$ by DLS. In addition the AFM topography (height) measurements also indicated flattening (ca. 35 
nm) on mica, as shown in Fig. 4C. This may be due to the AFM observation under dry condition.

As the target DP of PMEA further increased up to 300, it was difficult to control the dispersion polymerization even at $10.0 \mathrm{wt} \%$ solids concentration. This is likely because $\mathrm{PEO}_{45}$ was too short of a steric stabilizer to prevent precipitation. However, in these diblock copolymers (entries 1-4), no differences were seen on the morphology with the increasing solids concentration, i.e., only spherical micelles were obtained using $\mathrm{PEO}_{45}$ macro-CTA.

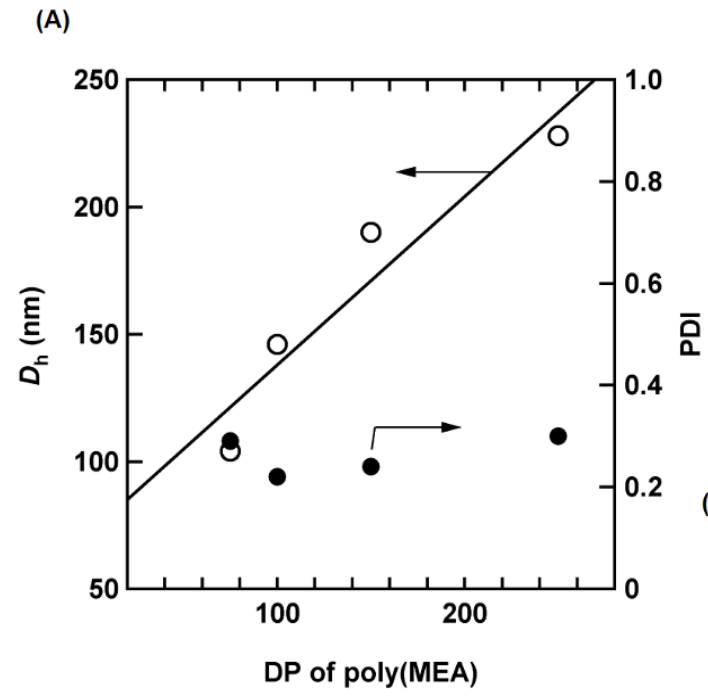

(B)

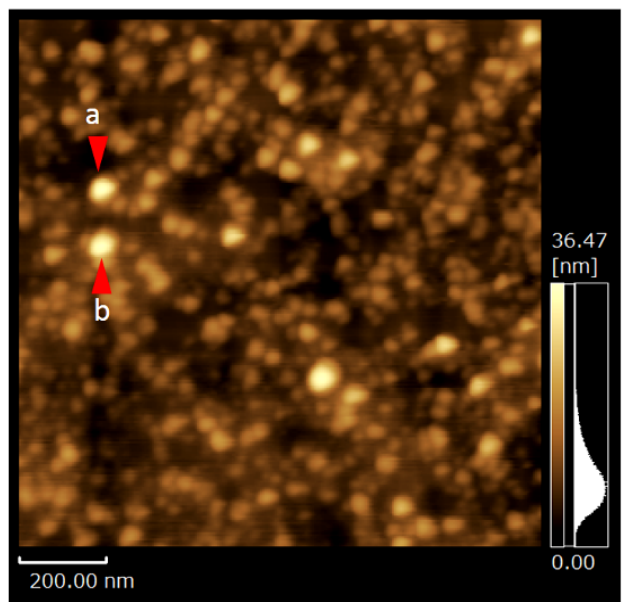

(c)

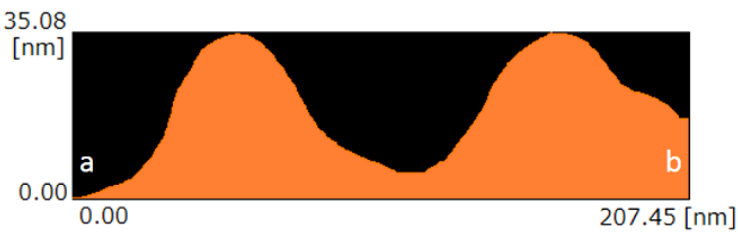

Fig. 4. (A) Variation of $D_{\mathrm{h}}$ and PDI with $D P$ of PMEA for $\mathrm{PEO}_{45}-b-\mathrm{MEA}_{\mathrm{m}}(\mathrm{m}=75-250)$ diblock copolymer assemblies (entries 1-4). (B) Representative AFM (height) image of spheres for $\mathrm{PEO}_{45}-b-\mathrm{MEA}_{75}$ diblock copolymer assemblies (entry 1, synthesized at $25.0 \mathrm{wt} \%$ solids concentration). (C) Cross-sectional profile was obtained from the line A-B on the image. 
Intriguingly, when $\mathrm{PEO}_{113}$ macro-CTAs were used in the RAFT aqueous dispersion polymerization with MEA, various morphology transitions were observed. In the case of $\mathrm{PEO}_{113}-b-\mathrm{MEA}_{300}$ diblock copolymers (see entries 5-10), it became clear that the transition of self-assembly occurred as the solids concentration changed. Fig. 5 shows AFM (height) images of the largest spheres (Table 1, entry 6) and threshold morphology (entry 7) between spheres and worms, at solids concentrations of 10.0 and $15.0 \mathrm{wt} \%$, respectively. Although these are identical block copolymers, the different solids concentration in polymerization gave different morphologies.
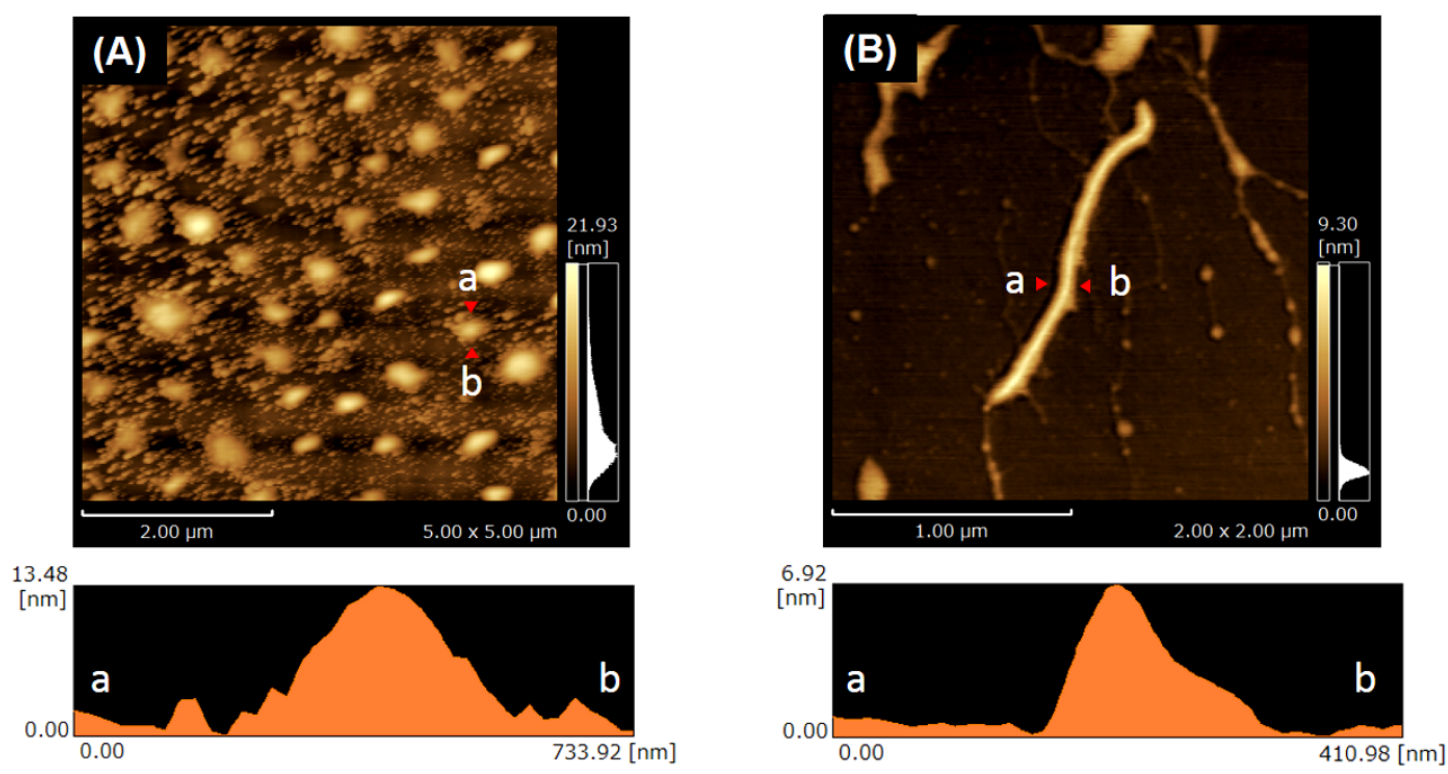

Fig. 5. Representative AFM (height) images with the cross-sectional profiles of (A) spheres and (B) worms and spheres for entries 6 and 7, respectively. 
Fig. 6A summarizes the variation of $D_{\mathrm{h}}$ and PDI with solids concentration (5.0-25.0 wt\%) for all the polymerizations for $\mathrm{PEO}_{113}-b$-MEA $\mathrm{M}_{300}$ diblock copolymer assemblies including entries 5-7. From the DLS studies, the spheres of $130-160 \mathrm{~nm}$ in diameter changed into larger aggregates with a diameter of approximately $210 \mathrm{~nm}$ when the solids content increased from 5.0 to $15.0 \mathrm{wt} \%$. The PDI gradually became larger. At $17.5 \mathrm{wt} \%$, worms were clearly seen with an average (spherical) diameter of $323 \mathrm{~nm},>1 \mu \mathrm{m}$ length and broader PDI in Fig. 6B. The dispersion was sufficiently viscous solution. The morphology finally changed into vesicles with an average diameter of $276 \mathrm{~nm}$ as the solids concentration increased to $20.0 \mathrm{wt} \%$ in Fig. 6C. The formation of vesicles was decided from the dimple by AFM topography (height) measurement. A further increase to $25.0 \mathrm{wt} \%$ allowed the full transition into vesicles with diameters of $280 \mathrm{~nm}$. This means that worms were obtained in the narrow phase range from 16.0 to $18.0 \mathrm{wt} \%$, and that the final morphology with increased solids concentration was a vesicle. This variation as solids concentration increased was commensurate with the packing parameter change $[6,33]$. Moreover, it can be concluded that PEO with a longer chain $(D P=$ 113) can adequately stabilize aggregates in water of various morphologies. 
(A)

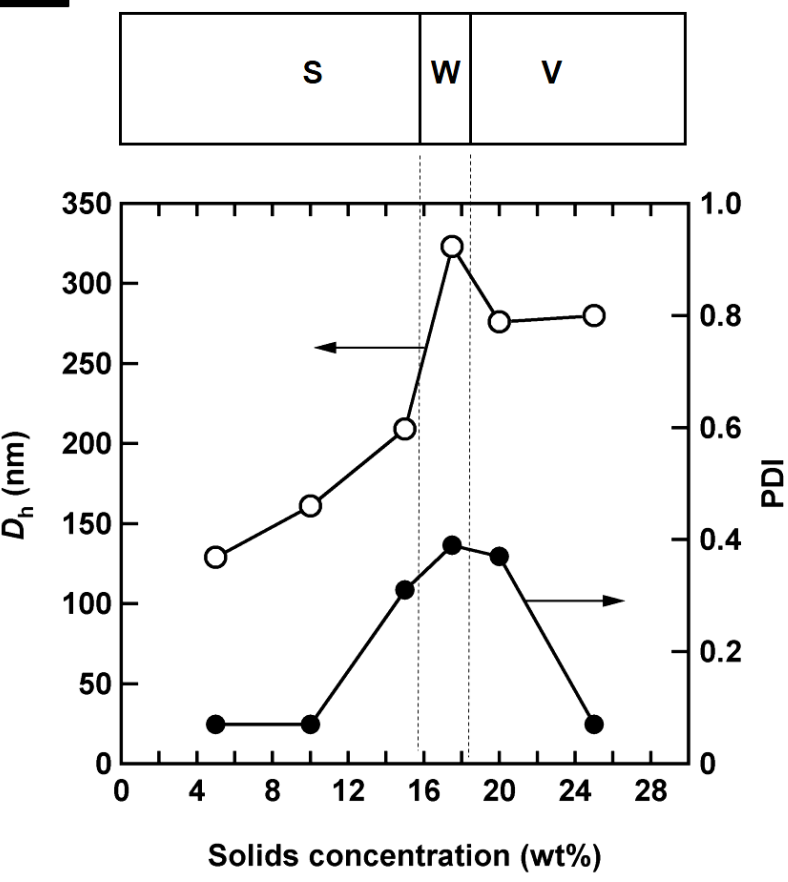

(B)

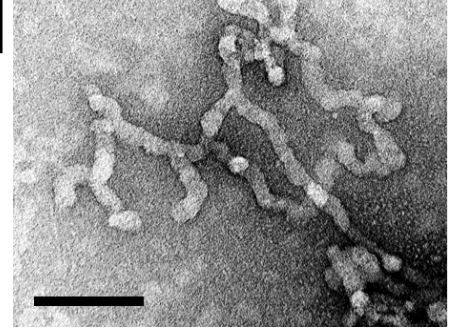

(C)

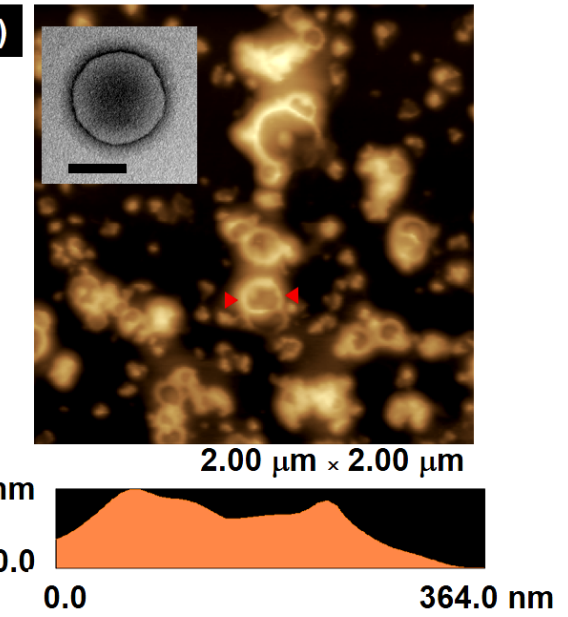

Fig. 6. (A) Variation of $D_{\mathrm{h}}$ and PDI with solids concentration (5.0-25.0 wt\%) for the polymerization of $\mathrm{PEO}_{113}-b$-MEA $\mathrm{M}_{300}$ diblock copolymer assemblies (including entries 5-10). Upper diagram shows morphological regions; S: spheres, W: worms and V: vesicles. The representative TEM image $(\mathrm{B})(\mathrm{bar}=100 \mathrm{~nm})$ and AFM (height) image with the cross-sectional profile (C) $(2.00 \times 2.00 \mu \mathrm{m})$ for entries 8 and 9, respectively. The inset in the AFM image (C) is the TEM image (bar = $200 \mathrm{~nm})$ for entry 9.

The length of PEO plays an important role in stabilizing the particle and not only imparts dramatic changes in particle diameter, but also determines various in situ self-assemblies in water. Here, PEO-b-PMEA block copolymers in entries 5-10 are identical (the same block length). Moreover, mere dilution of them with water did not lead to any change in the block 
copolymer morphology, confirmed by TEM, AFM and DLS measurements. This means that the resulting block copolymer aggregates in water are kinetically frozen.

When the target DP of PMEA increased to 400 using the same $\mathrm{PEO}_{113}$ macro-CTA (entries 11-14), spheres of $209 \mathrm{~nm}$ diameter and vesicles of $350 \mathrm{~nm}$ diameter were obtained at the solids concentration of 15.0 and $30.0 \mathrm{wt} \%$ as shown by the SEM and AFM analysis in Fig. 7. The DLS results and the relationship between $D_{\mathrm{h}}$, PDI and solids concentration are shown in Fig. 8. The difference was determined from the presence of a dimple in the AFM height image of dried samples, which was also observed in the SEM image of vesicles. In the case of the $\mathrm{PEO}_{113}$ macro-CTA, no worms were observed. In practice, a two-step change in $D_{\mathrm{h}}$ was observed in Fig. 8 (15.0 wt\% vs. 20.0-30.0 wt\%). Thus, the unobserved worm phase may occupy a much narrower region in the series of $\mathrm{PEO}_{113}-b-\mathrm{MEA}_{400}$ than that of $\mathrm{PEO}_{113}-b-\mathrm{MEA}_{300}$. On the basis of these results, this morphology transition of $\mathrm{PEO}_{113}-b-\mathrm{MEA}_{\mathrm{m}}$ occurred under the influence of the DP of the core block, PMEA and the total solids concentration on the final morphology as well as that of PMPC- $b$-PHPMA formulation previously reported [6]. In other words, the production of spheres, worms and vesicles can be tuned and enables the facileness and effective preparation of various self-assemblies by directly changing the concentrated aqueous solution. Since both PEO and PMEA have similar characteristics as biocompatible polymers, they hold great promise for biomedical applications. 
Solids conc. $=15.0 \mathrm{wt} \%$
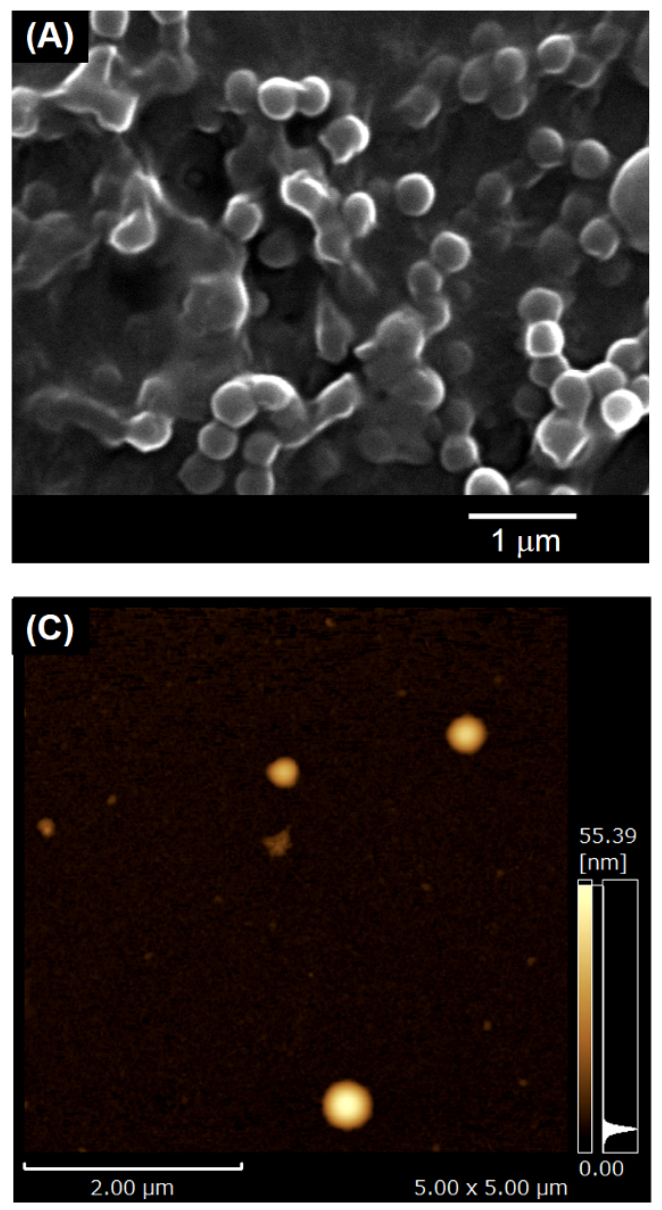

Solids conc. $=\mathbf{3 0 . 0} \mathrm{wt} \%$
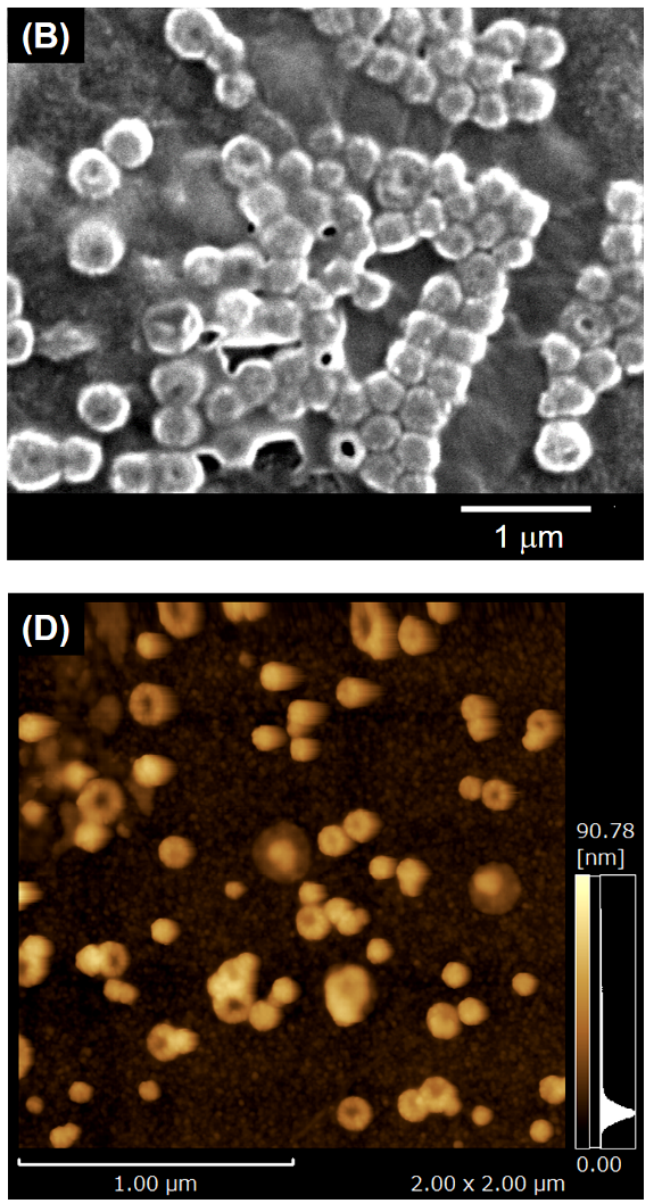

Fig. 7. SEM (A and B) and AFM (C and D) images of $\mathrm{PEO}_{113}-b-\mathrm{MEA}_{400}$ diblock copolymer morphologies polymerized at different solids concentrations of (A and C) $15.0 \mathrm{wt} \%$ and (B and D) $30.0 \mathrm{wt} \%$. 

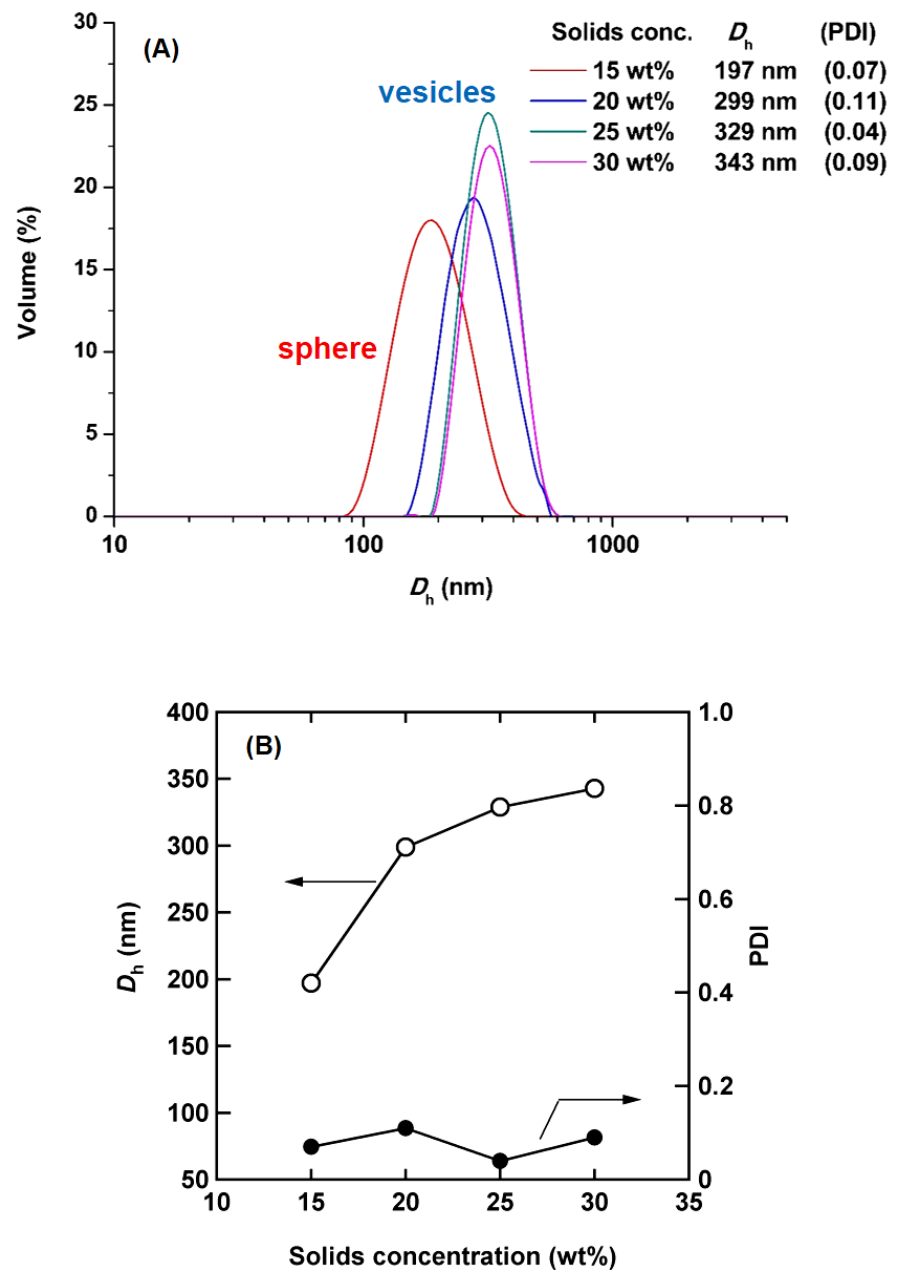

Fig. 8. (A) DLS particle size distributions (volume vs. mean hydrodynamic diameter, $D_{\mathrm{h}}$ ) and (B) the relationships between $D_{\mathrm{h}}$ or PDI and solids concentration for the resulting $\mathrm{PEO}_{113}-b$-PMEA 400 under RAFT aqueous dispersion polymerization of MEA using $\mathrm{PEO}_{113}$ macro-CTA.

\section{Conclusions}


In conclusion, a convenient and feasible method to prepare various morphologies has been developed via RAFT aqueous polymerization using $\mathrm{PEO}_{113}$ macro-CTA as a steric stabilizer in the appropriate composition and/or the total solids concentration. As an application for DDS, worms and vesicles are more preferable and efficient for circulation time and cell entry than spherical micelles [20,34]. In this report, we revealed that facile and direct preparation of various morphologies can be obtained by tuning a series of $\mathrm{PEO}_{113}-b-\mathrm{PMEA}_{300}$ (sphere, worm, and vesicle) and $\mathrm{PEO}_{113}-b$-PMEA 400 diblock copolymers (sphere and vesicle). We anticipate that these PEO-b-PMEA formulations will be useful for biomedical applications.

\section{Acknowledgements}

This work is supported by the PRESTO program on "Molecular Technology and Creation of New Functions” from JST, Japan.

\section{References}

[1] (a) Chiefari J, Chong YK, Ercole F, Krstina J, Jeffery J, Le TPT, Mayadunne RTA, Meijs GF, Moad CL, Moad G, Rizzardo E, Thang SH. Macromolecules 1998; 31: 5559-62; (b) Moad G, Rizzardo E, Thang SH. Aust J Chem 2005; 58: 379-410.

[2] Mai Y, Eisenberg A. Chem Soc Rev 2012; 41: 5969-85.

[3] Hillmyer MA, Bates FS, Almdal K, Mortensen K, Ryan AJ, Fairclough JPA. Science 1996; 271: 976-8.

[4] Wang X, Guerin G, Wang H, Wang Y, Manners I, Winnik MA. Science 2007; 317: 644-7.

[5] Pochan DJ, Chen Z, Cui H, Hales K, Qi K, Wooley KL. Science 2004; 306: 94-7. 
[6] Sugihara S, Blanazs A, Armes SP, Ryan AJ, Lewis AL. J Am Chem Soc 2011; 133: 15707-13.

[7] Sugihara S, Armes SP, Blanazs A, Lewis AL. Soft Matter 2011; 7: 10787-93.

[8] Sugihara S. Kobunshi Ronbunshu 2012; 69: 567-79.

[9] Li Y, Armes SP. Angew Chem Int Ed 2010; 24: 4042- 4046.

[10] Blanazs A, Madsen J, Battaglia G, Ryan AJ, Armes SP. J Am Chem Soc 2011; 133: 16581-87.

[11] Warren NJ, Mykhaylyk OO, Mahmood D, Ryan AJ, Armes SP. J Am Chem Soc 2014: 136; 1023-33.

[12] Rieger J, Grazon G, Charleux B, Alaimo D, Jérôme C. J Polym Sci Part A Polym Chem 2009: 47; 2373-2390.

[13] Zhou W, Qu Q, Xu Y, An Z. ACS Macro Lett 2015: 4; 495-499.

[14] Zhou W, Qu Q, Xu Y, An Z. ACS Macro Lett 2014: 3; 1220-1224.

[15] Fielding LA, Derry MJ, Ladmiral V, Rosselgong J, Rodrigues AM, Ratcliffe LPD, Sugihara S, Armes SP. Chem Sci 2013; 4: 2081-7.

[16] Yang P, Ratcliffe LPD, Armes SP. Macromolecule 2013; 46: 8545-56.

[17] (a) Wan W-M, Sun X-L, Pan C-Y, Macromolecules 2009; 42: 4950-2; (b) Wan W-M, Sun X-L, Pan C-Y. Macromol Rapid Commun 2010; 31: 399-404.

[18] Pei Y, Lowe AB, Polym Chem 2014; 5: 2342-51.

[19] (a) Boissé S, Rieger J, Belal K, Di-Cicco A, Beaunier P, Li M-H, Charleux B. Chem. Commun. 2010; 46: 1950-2; (b) Zhang X, Boissé S, Zhang W, Beaunier P, D’Agosto F, Rieger J, Charleux B, Macromolecules 2011; 44: 4149-58.

[20] Karagoz B, Esser L, Duong HT, Basuki JS, Boyer C, Davis TP. Polym Chem 2014; 5: $350-5$. 
(b) Sun J-T, Hong C-Y, Pan C-Y. Soft Matter 2012; 8: 7753-67; (c) Warren NJ, Armes SP. J Am Chem Soc 2014; 136: 10174-85, (d) Rieger J. Macromol Rapid Commun 2015; 36: 1458-1471.

[22] Liu G, Qiu Q, Shen W, An Z. Macromolecules 2011; 44: 5237-45.

[23] van Vlerken LE, Vyas TK, Amiji MM. Pharm Res 2007; 24: 1405-14.

[24] Nomoto T, Matsumoto Y, Miyata K, Oba M, Fukushima S, Nishiyama N, Yamasoba T, Kataoka K. J Controlled Release 2011; 151: 104-9.

[25] Tanaka M, Motomura T, Kawada M, Anzai T, Kasori Y, Shiroya T, Shimura K, Onishi M, Mochizuki A. Biomaterials 2000; 21: 1471-81.

[26] Mueller X, Jegger D, Augstburger M, Horisberger J, Von Segesser LK, Int J Artif Organs 2002; 25: 223-9.

[27] Steinhauer W, Hoogenboom R, Keul H, Moeller M. Macromolecules 2010; 43: 7041-7.

[28] Lai JT, Filla D, Shea R. Macromolecules 2002; 35: 6754-6.

[29] Rieger J, Stoffelbach F, Bui C, Alaimo D, Jérôme C, Charleux B. Macromolecules 2008; 41: 4065-8.

[30] Boursier T, Chaduc I, Rieger J, D’Agosto F, Lansalot M, Charleux B, Polym Chem 2011; 2: 355-62.

[31] Bütün V, Armes SP, Billingham NC. Polymer 2001; 42: 5993-6008.

[32] Zhang W, D’Agosto F, Boyron O, Rieger J, Charleux B. Macromolecules 2011; 44: 7584-93.

[33] Antonietti M, Förster S. Adv Mater 2003; 15: 1323-33.

[34] (a) Geng Y, Dalhaimer P, Cai S, Tsai R, Tewari M, Minko T, Discher DE, Nat 
Nanotechnol 2007; 2: 249-55; (b) Christian DA, Cai S, Garbuzenko OB, Harada T, Zajac AL, Minko T, Discher DE. Mol Pharmaceutics 2009; 6: 1343-52. 


\section{GRAPHICAL ABSTRACT}

\section{AUTHOR NAMES}

Shinji Sugihara,* Akmal Hadi Ma’Radzi, Shota Ida, Satoshi Irie, Takamaru Kikukawa, Yasushi Maeda

*Correspondence to Shinji Sugihara

\section{TITLE}

In situ nano-objects via RAFT aqueous dispersion polymerization of 2-methoxyethyl acrylate using poly(ethylene oxide) macromolecular chain transfer agent as steric stabilizer

\section{GRAPHICAL ABSTRACT FIGURE}

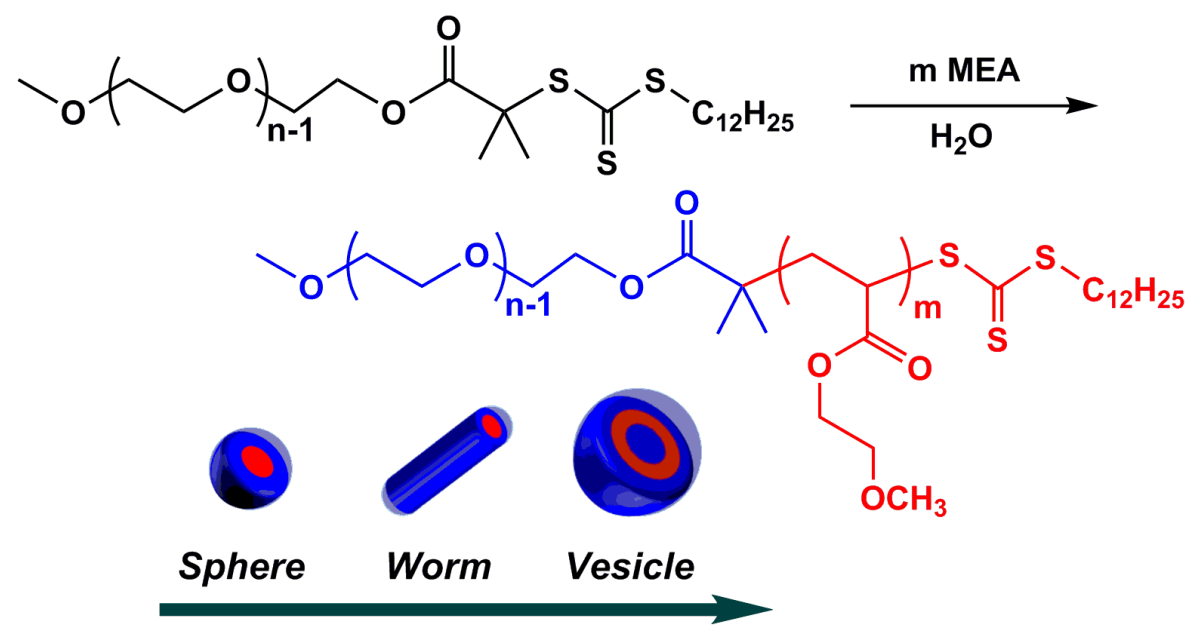

Solids concentration in polymerization \& DP of PMEA 